\title{
Retraining of drug reward, music cues and state-dependent recall in music therapy
}

\begin{abstract}
Brain research revealed that pleasant music appreciation is processed in same brain reward areas as euphoriant drugs. This indicates a similarity in processing intensity of emotions in the brain. These insights shed a new light on how music and emotion are linked in the brain. However, patients, with a history of drug-induced euphoria, may experience a statedependent recall induced from certain individually perceived cues, which have been experienced together with drugs, as memory traces are stored as conditioned secondary rewards in drug memory. Music's state-dependent cognition processes seem to be recalled (and thereby also the drug action) when listening to music without being under the influence. These learning processes have to be focused and transformed in therapy by offering new ways of learning to recognize, retrain and integrate state-specific emotional responses to preferred music to rebalance emotion and experiencing reward.
\end{abstract}

Keywords: Addiction, pleasure, state-dependent recall, drug cues, 
The Rolling Stones released their LP Aftermath including the song 'Mother's Little Helper' in the summer of 1966, a time when drugs became popular. Legal and illegal aspects of drug use where questioned from the youth' counterculture ${ }^{1}$. By singing about what happens at home and how easy it was to receive a GP's prescription for sedatives, the lyrics pointed out the contradiction of existing, tolerated ways to maintain mother's identity and functioning in society (... goes running for the shelter of her mother's little helper ... And it helps her on her way, gets her through her busy day. (Jagger/Richards 1966), while at the same time mind-altering drugs were in disrepute but despite of this quite popular in the counterculture 2,3 .

Every decade of debating drugs has produced differing strategies of how and why to treat those that are addicted ${ }^{4}$. Some authors discuss psychotropic substance seeking as a human evolutionary adaptation behaviour ${ }^{5}$ and that external stimulation of the brain reward system with plant toxins was important to stimulate its growth and separation from other species ${ }^{6,7}$. Drugs are tools that humans have developed or discovered for various purposes and, like all tools, they can be used or misused ${ }^{8}$. Using and misusing drugs is an old phenomenon and seems to be one of the anthropological constants of mankind like eating, drinking, sex, and war. It has always been a social problem that the misuse of drugs influences some people more than others.

Social pharmacology is a discipline of pharmacology that focuses on the usage of drugs as consumption behaviour. These behaviours are observed and described in their social environments and are interpreted with pharmacological, sociological, and psychological methods. The aim of this approach is to understand or describe patterns of use and resulting risk behaviour ${ }^{9-12}$. While an antidepressant maybe adequate for moderate or severe depression it may not be the right choice for the first episode of mild depression. However antidepressant prescriptions are on the rise ${ }^{13}$ and once the proposed 'chemical imbalances' are treated with antidepressants, it "may reduce sense of self and soul into dopamine, serotonin, neurons, milligrams" ${ }^{14}$.

A strong argument against the use of any psychotropic substance including alcohol is that they may temporarily open up capacities for relaxation or agitation, they may help to focus or un-focus attention, in- or decrease distance to own emotions, etc., in short, they may show the individual what is possible if the hurdles are gone and point out what has not been recognized before ${ }^{7}$. Already Baudelaire ${ }^{15}$ described that the state experienced under the influence may suggest that this is not much different from moments of bliss in which all seemed to go well (without the pills) however, depending on the pharmacokinetic anddynamic of substance and habituation involved the danger arises to build one-self on slippery ground of a 'medicated me' and a "false sense of well-being" ${ }^{14}$. Or as Eric Clapton described his perpetuation into addiction:

"To begin with, drink is very baffling and cunning. It's got a personality of its own. Part of the trap [of drugs and alcohol] is that they open the doors to unreleased channels or rooms you hadn't explored before or allowed to be open. A lot of my creative things came out first of all through marijuana. I started smoking when I was about eighteen or nineteen, and that would let out a whole string of humorous things as well as music. Then drink allowed me to be very self-piteous and opened up that whole kind of sorrowful musical side of myself. 
Unfortunately after that, the booze becomes more important than the doors it's opening, so that's the trap" Eric Clapton in Boyd 1992, p. $199^{16}$.

\section{Music, emotion and drug reward}

Music and drugs seem to go together and each change our emotions. Not only the manifold use and misuse of recreational drugs and alcohol in popular music culture has indicated this 17-19; brain research shows that preferred, pleasing music is processed in same areas as recreational euphoriant substances ${ }^{20}$, increasing cascades of dopaminergic interactions in cognition and reward systems ${ }^{21,22}$. Intense musical emotions and intoxication appear to have forms of emotional processing in common, at least in regard to reward processing in the limbic system of the brain.

In pleasure, desire, and lust, the dopamine system is active in a tonic and a phasic way. First, the tonic component of dopamine release in the prefrontal cortex of the brain regulates the readiness to react to stimuli. Second, there is an increase in dopamine release (phasic) when meaningful objects are in the focus of attention; the more dopamine is released, the higher is the personal meaning and valence of the object in focus. Dopamine's action supports to feel and distinguish where and when to place attention, what in this particular moment is of personal importance and which current selection of perceptual and emotional content is consciously processed. All drugs of abuse increase dopamine release and therefore affect these two ways of dopaminergic functioning ${ }^{23}$. As a result of unconscious sensory input changes under the influence of the drugs taken, a variety of possible neurotransmitter interactions will start to modulate the experience of pleasure.

Music promotes positive mood states, including euphoria, and to enable emotional regulation ${ }^{24}$. Music can provide a means for promoting positive mood states ${ }^{25}$ and -with some caution on the choice of the musical material (see below)-, it may help against the risk of relapse that is associated with negative mood states ${ }^{26}$. Psychoactive substances, as well as physical stimuli or behavioural patterns perceived as pleasurable, have reinforcing properties that can be ascribed to the neuronal reward system. The complex systems of neurotransmitters interacting with the nervous system to arouse euphoria are not yet satisfactorily understood. The reward system theory postulates that reaching pleasurable or euphoric states is the major goal of drug users and addicts; further, that emotional assessment of occurrences leads to the preference for states that are perceived as pleasant by the nervous system. Psychoactive drugs as well as specific behavioural patterns can activate the rewarding system and are therefore used to close the cycle of motivationsearch-fulfilment ${ }^{27}$. Drug-induced positive moods and states of euphoria, listening to preferred music or other pleasing activities like eating, sex, or play is mediated through the brain reward system. Eating chocolate or a refreshing drink with some sugar, as well as various other activities, can also activate the reward system ${ }^{28}$.

The isomorph activation of pleasure induced by drug action and listening to music may give rise to the hope that music used therapeutically, stirring up the emotions of the individual client, may reduce medication prescribed for mental health issues, as music can take over or support desired drug effects. Music can be employed as an adjunct to anaesthetic medication ${ }^{29,30}$ where sedatives are regularly administered before surgery to reduce 
patient's anxiety. However, sedatives often have negative side effects (drowsiness, respiratory depression, etc.), and may interact with anaesthetic agents, prolonging patient recovery and discharge. Therefore, increased attention is being paid to music to reduce medication during ${ }^{31}$ and anxiety before ${ }^{32}$ surgery.

Research on gambling addiction treatment shows that it is the habit and its specific reward functions ${ }^{33}$ that fosters the addictive habituation and not necessarily a substance. Physioacoustic relaxation-induction and creative work on recall of addictive states and motivation helped to overcome gambling ${ }^{34}$. Exposure to slow pulsations and monochrome sound induces a relaxation response shifting attention focus and altering consciousness ${ }^{35,36}$. In a study with depressed clients comparing treatment with Indian 'relaxation' music or hypnotics the authors discussed that "the effects of music could be equivalent to $10 \mathrm{mg}$ of Chlordiazepoxide or $7 \mathrm{mg}$ of Diazepam" ${ }^{37}$.

Altering consciousness has been successfully employed in addiction treatment where, for example in drum circles, consciousness is altered in extended drumming inducing the pleasure of playing and trancing in a group, shifting attention away from the drug into experiencing a cohesive and mutual activity of musicking ${ }^{38}$. Metzner described the relationship of addiction and dependence to the dynamics of consciousness in general and the alteration of consciousness in particular ${ }^{39}$. In his model, addiction is represented by an extremely narrow, focused scope or even point of consciousness. In contrast, altered states of consciousness are time-limited states in which the patterns of thought, feeling, and mood of perception and sensation are altered from the ordinary baseline conditions.

\section{Drug memory and music related relapses}

However, addictive drugs do hijack the reward system by external flooding of the corresponding receptors in the synaptic cleft, creating a temporary unspecific reward shift and by habituation a desensitised reward response ${ }^{40}$. Such addictive processes reflected on the endogenous level are not known so far in music appreciation but some caution has to be placed here. Recent findings in the neurobiology of addiction research using brain-imaging techniques provide insights into the development of addiction involving anatomic and functional connections between hippocampal and amygdala structures that modulate emotions and regulate affects, i.e. we are looking at state-specific learning and memory processes related to drug specific sensitization ${ }^{41,42}$, and such processes may also affect music-evoked emotions experienced under the influence of drugs. Treating addiction with music therapy may help clients to retrain and relearn the state-dependent recall of intense emotions experienced during intoxicated music appreciation ${ }^{43}$.

Pleasure, lust, and desire are essential evolutionary programs that guarantee reproduction and satiation and are mediated by the feeling that something we like has happened ${ }^{44}$. Intense emotions connected to pleasure, lust, and desire connotates the valence and meaning of an experience and inform about the salience of an event being different from normal. Depending on the stimulus, we may develop an increasing desire to experience this intensity again. However, pleasure and desire are regulated in different ways. Pleasure is the state in which we feel satiated, happy, and well, and which is sought to happen. Desire, or lust, is the drive that brings us to this state but has a mechanism of its own. Although 
pleasure is mainly mediated by the dopamine system, a longing for satisfying experiences like the taste of chocolate remains even when dopamine release is inhibited.

\section{Drug Sensitization and Neuroplasticity}

When it comes to drugs, the separation of pleasure and desire is the trickiest trap for the consumers on their way from drug use to abuse. Addiction research has identified the two "culprits" for this process of drug sensitization. While dopamine levels rise after drug ingestion, a protein that serves as a nuclear transcription factor-abbreviated as CREB (stands for CAMP [cyclic adenosine monophosphate] response element-binding)- is released, and this leads to a reduced sensitivity of the reward system to the drug. Another transcription factor called DeltaFos-B then comes into action and acts like a drug memory concerning the amount of reward the drug has offered ${ }^{45,46}$. This memory trace increases its somatic impact with the amount of drug use. As the CREB release is terminated after drug action, the DeltaFos-B activity and its corresponding information stays stable, inducing a memory trace that makes the consumer long again for that experience ${ }^{44}$.

However, this process of sensitization also happens with other rewarding pleasure experiences like sex or satiation after food. The context of drug use and the experiences of the rewards-the social setting and psychological state-contribute associations to the experience of both pleasure and dependence. The brains of cocaine addicts activate the same way when watching some else use coke as when they themselves use it; even just seeing the paraphernalia may stimulate the brain's reward centers. Drugs act directly on the neurotransmitter systems of the brain; therefore, the remaining drug memory trace is very strong. Opioid and dopamine signal pathways bypass orbitofrontal control functions, and the memory traces induced by DeltaFos-B alert the pleasure-seeking system when cues associated with the drug experience are present ${ }^{44}$. If this cue has become certain music or an associated lifestyle and arouses the person within a state-dependent recall ${ }^{18,43}$, the desire or craving (the narrowed scope of searching for immediate satisfaction) starts again.

\section{State-specific recall}

'State-dependent learning is a phenomenon in which the retrieval of newly acquired information is possible only if the subject is in the same sensory context and physiological state as during the encoding' ${ }^{47}$. State-dependent perceptual learning processes might resemble those occurring during therapy processes. The experience and perception of musical elements like rhythm, loudness and pitch is recalibrated and reframed under the influence of drugs ${ }^{48}$. However, the music's state-dependent cognition processes seem to be recalled (and thereby also the drug action) when listening to music without being under the influence. We know that Musicians like the Beatles used their own psychedelic experience to produce music that seems to be more appreciated under the influence (as for example their album Sgt Pepper's Lonely hearts Club Band from 1967) because the composers had the experience of the perceptual change experienced in the altered state of drug action 48,49 . We can imagine that once a client has experienced, and connected, a primary drug reward with cultural objects and lifestyle in popular culture, the cultural object associated with this lifestyle will be transformed into a secondary reward symbol. Thus, emotional cascades of state-related drug memory will be reactivated when certain cues are heard in the music, or 
during events in dance, and this may interfere with the aims of therapists. Such problems are not 'in the music', or the substance itself, but connected to the brain reward system, which is linked to perceptual learning and habituation of emotional states like euphoria, flow, joy or pleasantness ${ }^{44}$.

Patients, with a history of drug-induced euphoria, may experience a state-dependent recall induced from certain individually perceived cues, which have been experienced together with drugs, as memory traces are stored as conditioned secondary rewards in drug memory ${ }^{50}$. Research on the state-dependent effects of music on mood and behaviour refer to individual perceptual learning strategies and history under the influence of drug action ${ }^{51,52}$.

However, the connection of joyful experiences intensified by drug action is producing a strong memory account and craving for such situations might lead to an addiction. Hereby the addictive potential of different drugs and their specific pharmaco-kinetic and -dynamics has to be taken into account ${ }^{53}$. These learning processes have to be focused and transformed in therapy by offering new ways of experiencing.

\section{Implications for music therapy}

We discussed one stream of current research that links the euphoria induced by drugs and also by music. Since Blood and Zatorre in $2001^{20}$ have pointed out the underlying similarities between the pleasing effects of preferred music and euphoretic drug action, there have been several investigations from the music sciences into the corresponding brain mechanisms. For music therapists working with addicted clients, this research stream gives hope that there are isomorphic activities to its processing and music used in therapy may help to reframe the emotions focussing solely on the drug action.

\section{Different drugs and experience profiles}

However, when it comes to different drugs, we have to be aware that there are differing profiles to the drug action sought from clients. Social pharmacologists would describe the drug taking habits and the specific effects that are sought from addicts, also describing the drug use of musicians and their audience 9,54,55 17 .

A common quality of all psychoactive drugs is that they alter the evaluation of sensory input and its conceptual comparison and assessment with known information ${ }^{27}$. Heroin is both a euphoriant and a strong sedative, ${ }^{40}$ and increases an emotion that keeps the sensual world at a 'cool' distance. Opioids, the body's own painkiller, diminish external input by dampening the bottom-up sensory transmission. Drugs with a relatively solid internal assessment (like Opioids are to a large extent independent from situational cues. These drugs have a hermetic or closed, context-independent and immediate effect on pain and tension while acting on the primary mesolimbic centers of assessment. They induce pleasurable states with the accordant reinforcement properties independent of contextual or situational cues. In contrast, drugs with a contextual bonding and assessment (like cannabis and hallucinogens) are more situational in their effect. Emotions and perceptions mediated by the hippocampal comparator systems modulate the drug effect much more than drugs with a solid internal assessment ${ }^{7}$. 
How different drug actions relate to music perception cannot easily be generalised, and research into this field of the music sciences is still in its infancy. A systematic investigation into the meaning of music for drug addicts as investigated by Horesh ${ }^{56,57}$ and the effect of drugs on music perception and production ${ }^{48,58}$ would enrich the understanding of music, drugs and reward. Keith Richards, for example, used to call some of his guitar work relating to his time being a Heroin addict as 'there I am playing my junkie riffs' ${ }^{59}$. What this may mean in terms of the musical elements used is left open for further research. But as with Keith Richards and others that spiralled into addictions, drugs and music accompanied important and also difficult periods in their lives (see quote from Eric Clapton above). Therefore, any music experienced during such periods will relate to the autobiographical memory traces of the clients and their drug use experience. This is what many music therapists working with addicted clients know and many have to find ways around the client's difficult responses to music. Nevertheless, what we need are more distinct descriptions of how music therapists did this and with which drugs and music the clients were struggling.

\section{Gaining awareness for music-related drug cues}

Since music readily impacts neural activity, special consideration is necessary when therapeutically using music with people with addictions. Individuals with addictions can experience a decrease in substance craving after listening to songs that they identify as helping them stay clean/sober and reduce negative emotions ${ }^{60,61}$. But they may likewise experience an increase in substance craving after listening to songs that they identify with substance use ${ }^{62}$. A recent review ${ }^{63}$ on the appreciation of sad music indicated that certain pieces of music, especially when they are representing the individual 'grief-stricken sorrow' of negative life-events, can be a threat to those repeatedly listening to them. Thus, we cannot simply expect that listening to sad music is just enjoying and romanticizing a 'comforting' and 'sweet sorrow' feeling or a temporary cathartic tool to overcome rumination on sad life events. However, music therapists are trained to develop adequate empathic sensitivity and immediately sense the different forms of meaning revealed through individual music appreciation in order to work with this material in a responsible way. Thus, gaining awareness of healthy and unhealthy uses of music ${ }^{64}$, and considering how context impacts on how music is perceived ${ }^{65}$ are important aspects of music therapy within addiction treatment. Furthermore, It seems that the personality trait reward sensitivity that underlies problematic substance use also underlies involvement in a range of music activities, and this link is mediated by emotional sensitivity to music and attentional absorption in music ${ }^{66}$. However, Horesh demonstrated how musical cues and music-related relapses can be successfully addressed and reversed in music therapy. Patients learned to recognize, retrain and integrate state-specific emotional responses to preferred music, that could potentially trigger memories of their former drug use bearing cues to the former culture of addiction as part of their biography ${ }^{56}$. Addictive processes narrow and recalibrate pathways and conscious choices for reward, but being involved in pleasing musical activities helps to reframe the narrowed focus of attention onto alternative opportunities of reward processing. Music therapy offers new strategies for retraining narrowed attention onto externally sought strong emotional processes. However, this implies that music therapist should reserve time to discuss with and find out about the music preferences of their addicted clients, facilitating their description of the music that they were enjoying under the 
influence. Nevertheless, given what we know about the strong memory account and mechanisms linked to the emotions experienced, one has to be cautious and conscious of the emotional impact that music can provide.

\section{References}

1. Whiteley S. The space between the notes - Rock and the counter culture. London: Routledge; 1992.

2. Markert J. Sing a song of drug use-abuse: Four decades of drug lyrics in popular music - From the sixties through the nineties. Sociological Inquiry 2001; 71(2): 194-220. 3. Manning P. Drugs and Popular Culture - Drugs, media and identity in contempory society. Cullompton: Willan Publishing 2007.

4. Szasz TS. Ceremonial chemistry : the ritual persecution of drugs, addicts, and pushers. Rev. ed. Syracuse, N.Y.: Syracuse University Press; 2003.

5. Sullivan RJ, Hagen EH. Psychotropic substance-seeking: evolutionary pathology or adaptation? Addiction 2002; 97(4): 389-400.

6. Sullivan RJ, Hagen EH, Hammerstein P. Revealing the paradox of drug reward in human Proceeding of the Royal Society B - Biological Sciences 2008; 2008275 1231-41; .

7. Blätter AE, Fachner JC, Winkelman M. Addiction - Dynamics and Relations to Altered States of Consciousness. In: Cardenas E, Winkelman M, eds. Altering Consciousness: A multidisciplinary perspective. Santa Barbara: Praeger; 2011: 167-87.

8. Moore P. Enhancing me : the hope and the hype of human enhancement. Chichester, England ; Hoboken, NJ: Wiley/Dana Centre; 2008.

9. Nencini P. The shaman and the rave party: social pharmacology of ecstasy. Subst Use Misuse 2002; 37(8-10): 923-39.

10. Gerhard H. Party-drugs: sociocultural and individual background and risks. International Journal of Clinical Pharmacology and Therapeutics 2001; 39(8): 362-6.

11. Gahlinger PM. Club drugs: MDMA, gamma-hydroxybutyrate (GHB), Rohypnol, and ketamine. American family physician 2004; 69(11): 2619-26.

12. Battisti MC, Noto AR, Nappo S, Carlini Ede A. A profile of Ecstasy (MDMA) use in Sao Paulo, Brazil: an ethnographic study. J Psychoactive Drugs 2006; 38(1): 13-8.

13. Lönnqvist J. Stressi ja depressio (Stress and depression). 2009. http://www.terveyskirjasto.fi/terveyskirjasto/tk.koti?p artikkeli=seh00020 (accessed January 19 2009).

14. Norris C. The medicated me. 20112011.

http://chrisnorriswordsandmusic.com/pages/stories/medicated.php (accessed 17th

October 2013).

15. Baudelaire C. Les paradis artificiels: opium et haschisch. Paris: Poulet-Malassis et de Broise; 1860.

16. Boyd J. Musicians in tune - Seventy-five contempory musicians discuss the creative process. 1 ed. New York: Fireside, a Simon \& Schuster imprimateur; 1992.

17. Shapiro H. Waiting For The Man - The Story of Drugs and Popular Music. 2 ed. London: Helter Skelter Publishing; 2003. 
18. Fachner J. Music and drug induced altered states. In: Aldridge D, Fachner J, eds. Music and Altered States - Consciousness, Transcendence, Therapy and Addictions. London: Jessica Kingsley; 2006: 82-96.

19. Van Havere T, Vanderplasschen W, Lammertyn J, Broekaert E, Bellis M. Drug use and nightlife: more than just dance music. Subst Abuse Treat Prev Policy 2011; 6: 18.

20. Blood AJ, Zatorre RJ. Intensely pleasurable responses to music correlate with activity in brain regions implicated in reward and emotion. Proc Natl Acad Sci U S A 2001; 98(20): 11818-23.

21. Menon V, Levitin DJ. The rewards of music listening: Response and physiological connectivity of the mesolimbic system. Neuroimage 2005; 28(1): 175-84.

22. Salimpoor VN, Benovoy M, Larcher K, Dagher A, Zatorre RJ. Anatomically distinct dopamine release during anticipation and experience of peak emotion to music. Nat Neurosci 2011; 14: 257-62.

23. Yacubian J, Büchel $C$. The genetic basis of individual differences in reward processing and the link to addictive behavior. In: Dreher J-C, Tremblay L, eds. Handbook of Reward and Decision Making. 1 ed. Burlington: Academic Press; 2009: 345-60.

24. Carlson E, Saarikallio S, Toiviainen P, Bogert B, Kliuchko M, Brattico E. Maladaptive and adaptive emotion regulation through music: a behavioral and neuroimaging study of males and females. Front Hum Neurosci 2015; 9: 466.

25. Koelsch S. Music-evoked emotions: principles, brain correlates, and implications for therapy. Ann N Y Acad Sci 2015; 1337: 193-201.

26. Koob GF. Dynamics of Neuronal Circuits in Addiction: Reward, Antireward, and Emotional Memory. Pharmacopsychiatry 2009; 42(S 01): S32-S41.

27. Emrich HM, Schneider U. Facetten der Sucht. Von der Neurobiologie zur Anthropologie Frankfurt a.M: Peter Lang; 2006.

28. Small DM, Zatorre RJ, Dagher A, Evans AC, Jones-Gotman M. Changes in brain activity related to eating chocolate: from pleasure to aversion. Brain 2001; 124(Pt 9): 172033.

29. Spintge R. Die therapeutisch-funktionalen Wirkungen von Musik aus medizinischer und neurphysiologischer Sicht - Musik als therapeutische Droge. In: Rösing H, ed. Musik als Droge? Zu Theorie und Praxis bewußtseinsverändernder Wirkungen von Musik. Mainz: Villa Musica; 1991: 13-22.

30. Spintge R. Clinical Use of Music in Operating Theaters. In: MacDonald R, Kreutz G, Mitchell L, eds. Music, Health, and Wellbeing. Oxford - New York: Oxford University Press; 2012: $277-86$.

31. Harikumar R, Raj M, Paul A, et al. Listening to music decreases need for sedative medication during colonoscopy: a randomized, controlled trail. Indian Journal of Gastroenterology 2006; 25(1): 3.

32. Bringman $\mathrm{H}$, Giesecke K, Thörne A, Bringman S. Relaxing music as pre-medication before surgery: a randomised controlled trial. Acta Anaesthesiologica Scandinavica 2009; 53(6): 759-64.

33. Reuter J, Raedler T, Rose M, Hand I, Glascher J, Buchel C. Pathological gambling is linked to reduced activation of the mesolimbic reward system. Nat Neurosci 2005; 8(2): 1478.

34. Erkkilä J, Eerola T. Gambling addiction: Evaluation of a multimethod treatment programme including music therapy In: Aldridge D, Fachner J, eds. Music Therapy and Addictions London and Philadelphia: Jessica Kingsley Publishers; 2010: 140-55. 
35. Fachner J, Rittner S. Ethno therapy, music and trance - An QEEG investigation into a sound-trance induction. In: Cvetkovic D, Cosic I, eds. States of Consciousness: Experimental Insights into Meditation, Waking, Sleep and Dreams Berlin: Springer; 2011: 233-54.

36. Lee EJ, Bhattacharya J, Sohn C, Verres R. Monochord sounds and progressive muscle relaxation reduce anxiety and improve relaxation during chemotherapy: a pilot EEG study. Complementary Therapies in Medicine 2012; 20(6): 409-16.

37. Deshmukh AD, Sarvaiya AA, Seethalakshmi R, Nayak AS. Effect of Indian classical music on quality of sleep in depressed patients: A randomized controlled trial. Nordic Journal of Music Therapy 2009; 18(1): 70-8.

38. Winkelman M. Complementary therapy for addiction: "drumming out drugs". Am J Public Health 2003; 93(4): 647-51.

39. Metzner R. Addiction and transcendence as altered states of consciousness. Journal of Transpersonal Psychology 1994; 26(1): 1-17.

40. Julien RM, Advokat CD, Comaty JE. A primer of drug action : a comprehensive guide to the actions, uses, and side effects of psychoactive drugs. 11th ed. New York, NY: Worth Publishers; 2008.

41. Zarrindast M-R, Rezayof A. Morphine state-dependent learning: sensitization and interactions with dopamine receptors. European Journal of Pharmacology 2004; 497(2): 197-204.

42. Eich JE. State-dependent retrieval of information in human episodic memory. In: Birnbaum IM, Parker ES, eds. Alcohol and Human Memory (PLE: Memory): Psychology Press; 2014: 141-58.

43. Fachner J. Music therapy, drugs and state-dependent recall. In: Aldridge D, Fachner J, eds. Music therapy and addictions. 1 ed. London: Jessica Kingsley; 2010: 18-34.

44. Esch T, Stefano GB. The neurobiology of pleasure, reward processes, addiction and their health implications. Neuroendocrinology Letters 2004; 25(4): 235-51.

45. McClung CA, Ulery PG, Perrotti LI, Zachariou V, Berton O, Nestler EJ. DeltaFosB: a molecular switch for long-term adaptation in the brain. Brain Research 2004; 132(2): 14654.

46. Nestler EJ. Molecular mechanisms of drug addiction. Neuropharmacology 2004; 47 Suppl 1: 24-32.

47. Shulz DE, Sosnik R, Ego V, Haidarliu S, Ahissar E. A neuronal analogue of statedependent learning. Nature 2000; 403(6769): 549-53.

48. Fachner J. Drugs, altered states and musical consciousness: reframing time and space. In: Clarke E, Clarke D, eds. Music and consciousness. Oxford: Oxford University Press; 2011: 263-80.

49. Böhm T. Was ist Psychedelic Rock? Zum Einfluß von Drogen auf die Musik am Beispiel der Beatles und LSD. In: Rösing H, Phleps T, eds. Erkenntniszuwachs durch Analyse Populäre Musik auf dem Prüfstand. 1 ed. Karben: Coda; 1999: 7-25.

50. Boening JA. Neurobiology of an addiction memory. Journal of Neural Transmission 2001; 108(6): 755-65.

51. Thaut $\mathrm{MH}$, de l'Etoile SK. The effects of music on mood - state-dependent recall. Journal of Music Therapy 1993; 30(2): 70-80.

52. Globus GG, Cohen HB, Kramer JC, Elliot HW, Sharp R. Effects of marihuana induced altered state of consciousness on auditory perception. Journal of Psychedelic Drugs 1978; 10(1): 71-6. 
53. Overton DA. Historical context of state dependent learning and discriminative drug effects. Behavioural Pharmacology 1991; 2(4-5): 253-64.

54. Baumeister RF. Acid rock: a critical reappraisal and psychological commentary. $J$ Psychoactive Drugs 1984; 16(4): 339-45.

55. Montagne M. Social Pharmacology: Integrating Pharmaceutical and Social Science Research on Drug Effects. Drug Information Journal 2004; 38(4): 315-20.

56. Horesh T. Drug addicts and their music - A Story of a Complex Relationship. In: Aldridge D, Fachner J, eds. Music therapy and Addictions. London: JKP; 2010: 57-74.

57. Horesh T. Dangerous Music -Working with the Destructive and Healing Powers of Popular Music in the Treatment of Substance Abusers In: Aldridge D, Fachner J, eds. Music and Altered States - Consciousness, Transcendence, Therapy and Addiction. London: Jessica Kingsley; 2006: 125-39.

58. Fachner J. "... if you're a viper." Consciousness states in a social pharmacology of music. In: Cavanna AE, Nani A, eds. Consciousness: States, Mechanisms and Disorders. Hauppauge NY Nova Science Publishers 2012: 189-206.

59. Riebe. Interview with Keith Richards. Fachblatt Musikmagazin. 1978 November. 60. Gebhardt S, Kunkel M, von Georgi R. Music helps addicted patients to reduce negative emotions in everyday life. Rearch Journal of Drug Abuse, 2014.

http://www.hoajonline.com/drugabuse/abstract/2057-3111/1/1 (accessed.

61. Fritz TH. Benefits of listening to a recording of euphoric joint music making in polydrug abusers. Frontiers in Human Neuroscience 2015; 9.

62. Short ADL, Dingle GA. Music as an auditory cue for emotions and cravings in adults with substance use disorders. Psychology of Music 2015.

63. Eerola T, Peltola HR. Memorable Experiences with Sad Music-Reasons, Reactions and Mechanisms of Three Types of Experiences. PLoS One 2016; 11(6): e0157444.

64. Saarikallio S, Gold C, McFerran K. Development and validation of the HealthyUnhealthy Music Scale. Child Adolesc Ment Health 2015; 20(4): 210-7.

65. McFerran KS. Contextualising the relationship between music, emotions and the well-being of young people: A critical interpretive synthesis. Musicae Scientiae 2016; 20(1): 103-21.

66. Loxton NJ, Mitchell R, Dingle GA, Sharman LS. How to tame your BAS: Reward sensitivity and music involvement. Personality and Individual Differences 2016; 97: 35-9. 